\title{
ARTIGO
}

DOI: $10.22481 /$ praxis.v14i28.3468

\section{O BOM PROFESSOR DE QUÍMICA NA VOZ DOS ESTUDANTES}

THE GOOD TEACHER OF CHEMISTRY IN THE STUDENT’S VOICE

\author{
EL BUEN PROFESOR DE QUÍMICA EN LA VOZ DE LOS ESTUDIANTES
}

\author{
Marcelle Moura Silveira \\ Universidade Federal de Pelotas - Brasil \\ Adriana Duarte Leon \\ Instituto Federal Sul-Rio-Grandense - Brasil
}

\begin{abstract}
Resumo
Este trabalho analisa a concepção dos estudantes em relação ao bom professor de Química e à boa aula de Química. A abordagem metodológica adotada neste trabalho baseia-se nos princípios de uma pesquisa qualitativa. A voz dos estudantes foi captada por meio de um questionário aberto aplicado no curso Técnico em Química, modalidade integrado, no Instituto Federal Sul Rio-Grandense, Campus Pelotas. Com o objetivo de contribuir com a formação e as práticas docentes que vêm sendo adotadas em nossas escolas, perguntamos aos discentes características que eles atribuem ao bom professor e à boa aula de Química. Como resultado, podemos perceber que o bom professor de Química, na voz dos estudantes, é multidimensional e envolve, ao mesmo tempo, características relacionadas à didática e à afetividade.
\end{abstract}

Palavras-chave: Estudantes; Prática docente; Química.

\begin{abstract}
:
This work analyzes the student's conception of a good chemistry teacher and a good chemistry class. The methodological approach adopted in this work is based on the principles of a qualitative research. The student's voice was captured by an open questionnaire applied in the Technical course in Chemistry, integrated modality of the Federal South Rio-Grandense Institute, Campus Pelotas. In order to contribute to the training and teaching practices that have been adopted in our schools, we ask to the students characteristics that they attribute to a good teacher and a good chemistry class. As a result, we can see that a good chemistry teacher, in the student's voice, is multidimensional and involves, at the same time, characteristics related to didactics and affectivity.
\end{abstract}

Keywords: Chemistry; Students; Teaching practice.

\section{Resumen}


Este trabajo analiza la concepción de los estudiantes en relación al buen profesor de Química y la buena clase de Química. El enfoque metodológico adoptado en este trabajo se basa en los principios de una investigación cualitativa. La voz de los estudiantes fue captada por medio de un cuestionario abierto aplicado en el curso Técnico en Química, modalidad integrada, en el Instituto Federal Sur RioGrandense, Campus Pelotas. Con el objetivo de contribuir con la formación y las prácticas docentes que vienen siendo adoptadas en nuestras escuelas, preguntamos a los estudiantes características que ellos atribuyen al buen profesor ya la buena clase de Química. Como resultado, podemos percibir que el buen profesor de Química, en la voz de los estudiantes, es multidimensional e involucra al mismo tiempo características relacionadas a la didáctica ya la afectividad.

Palabras clave: Estudiantes; Práctica docente; Química.

\section{Introdução}

O professor desempenha um importante papel no processo de ensino. Sua prática pedagógica influencia diretamente o desenvolvimento dos estudantes, personagens centrais, no processo ensino-aprendizagem. Assim, conhecer os aspectos considerados fundamentais pelos estudantes na prática de um bom professor ao ministrar uma boa aula é importante para auxiliar no planejamento de ações que contribuam para um ensino de melhor qualidade. $\mathrm{Na}$ perspectiva de Freire (2011, p. 83), ensinar exige curiosidade; "como professor devo saber que sem a curiosidade que me move, que me inquieta, que me insere na busca, não aprendo nem ensino". Assim, o educador deve ser capaz de potencializar a curiosidade nos educandos. Entretanto, estimular a curiosidade se consolida atualmente como um dos grandes desafios da prática docente, pois o professor concorre com inúmeros outros elementos, por vezes mais interessantes aos estudantes do que os conteúdos do ensino.

Nesse contexto, quando comecei minha formação docente, no Curso de PósGraduação Lato Sensu em Educação Profissional com Habilitação para Docência no Instituto Federal Sul Rio-Grandense (IFSUL), comecei a me questionar sobre o que deveria fazer para que os meus alunos se interessassem pelas minhas aulas, qual metodologia poderia contribuir para a aprendizagem deles? Corroborando com Nóvoa (1992), acredito que há uma estreita relação entre o trabalho docente e a qualidade de ensino e, assim, começaram as minhas inquietações em relação à prática docente. Busquei subsídios teóricos e metodológicos que pudessem contribuir não apenas com a minha formação, mas também com as práticas que vêm sendo adotadas nas escolas brasileiras.

Embora diversos órgãos institucionais valorizem o conhecimento como fator determinante para o exercício da docência, busca-se, neste trabalho, identificar aspectos que 
corroboram para a constituição de um bom professor e vão além da área específica do conhecimento.

Faz parte do senso comum, ratificado pelos órgãos institucionais, que o professor possua um saber que lhe é próprio. Esse saber possui duas grandes direções: o domínio do conteúdo de ensino, isto é, de seu próprio objeto de estudo, e o domínio das ciências de educação que lhe permitirão compreender e realizar o processo pedagógico. (CUNHA, 2010, p. 40)

Considerando a multiplicidade de elementos que constituem a prática docente, este trabalho identifica as características de um bom professor e de uma boa aula de Química a partir da voz dos estudantes; consequentemente, sugere alguns aspectos que precisam de maior atenção na formação docente, bem como anuncia algumas características valorizadas pelos discentes na prática e postura do professor. Sob inspiração de Cunha (2010, p. 26), quando afirma que "o educador se educa na prática da educação", busca-se, neste estudo, analisar a fala dos estudantes do curso Técnico Integrado em Química do IFSul Campus Pelotas com o objetivo de identificar e problematizar as características de um bom professor.

\section{Caminhos da pesquisa}

Para a realização deste trabalho, desenvolvemos uma pesquisa de natureza qualitativa, que teve como objetivo identificar, na perspectiva dos estudantes, o perfil de um bom professor de Química e as características de uma boa aula de Química. De acordo com Santos (2010), a pesquisa qualitativa nos permite refletir e analisar a realidade a partir da utilização de métodos e técnicas que possibilitam a compreensão detalhada do objeto de estudo.

A pesquisa qualitativa trabalha com o espaço das relações baseada em um universo de significados e atitudes. Valoriza a realidade dos sujeitos e os processos em análise, considerando tais aspectos como fundamentais para o entendimento de uma determinada situação problema: "toda investigação se inicia por uma questão, por um problema, por uma pergunta, por uma dúvida e a resposta a esse movimento do pensamento geralmente se vincula a conhecimentos anteriores" (MINAYO, 2012, p. 16).

No que se refere aos estudos relacionados à prática pedagógica, Cunha (2010) observa que as pesquisas qualitativas podem contribuir no sentido de identificar e analisar os aspectos agregados ao perfil de um bom professor. De certa forma, o que fazemos, neste trabalho, é identificar aspectos que os estudantes relacionam ao bom professor e à boa aula. Aspectos que 
estão vinculados à vivência dos discentes no universo escolar e contribuem para a constituição de suas aprendizagens em um campo específico do conhecimento.

Utilizamos como recurso metodológico, para captar a voz dos estudantes, um questionário com questões abertas, aplicado na turma do sétimo semestre do curso Técnico em Química do IFSul, modalidade integrado. Segundo Gil (2008), a aplicação de questionários como instrumento de pesquisa é uma técnica de investigação que tem como objetivo principal obter informações sobre conhecimento, valores, interesses e etc.

Escolhemos os estudantes do sétimo semestre, pois estão no último ano do curso Química Integrado, cabe observar que o curso é composto por oito semestres, sendo o último semestre ocupado majoritariamente por disciplinas vinculadas ao estágio final. O curso em questão é composto majoritariamente por jovens na faixa etária entre 15 e 21 anos que estudam no turno diurno e cursam de forma integrada o ensino médio e técnico. Escolhemos o sétimo semestre, pois esses estudantes já mantiveram contato com a maioria das disciplinas do curso e consequentemente com diversos professores da área específica de química. Acreditamos que essa maior vivência escolar contribui para o melhor preenchimento do instrumento de pesquisa. Entretanto, cabe observar que o objetivo do questionário não foi identificar nominalmente os bons professores, mas sim práticas e posturas que os educandos entendem como fundamentais na prática docente.

O questionário foi aplicado de forma coletiva, no último dia de aula da disciplina de Técnicas de Formulações Químicas. Como parte da logística de aplicação do questionário, inicialmente, foi explicitado o objetivo da pesquisa e posteriormente esclarecidas às questões individualmente. A turma pesquisada era composta por 16 alunos e todos aceitaram participar da pesquisa de forma voluntária. Para que os estudantes tivessem mais liberdade nas suas respostas e pudessem explorar mais suas ideias, optamos pelo uso de questões abertas e garantimos o anonimato dos mesmos. Além disso, foi solicitado uma quantidade mínima de linhas em cada resposta, mas não um número máximo, para que os estudantes descrevessem livremente as suas concepções sobre um bom professor e uma boa aula de Química.

Compreendendo a pesquisa como fundamental para analisar os processos que envolvem a subjetividade do sujeito, buscamos identificar o ideário do bom professor junto aos discentes, aplicando o questionário que desafiava os estudantes a refletirem sobre quais aspectos são fundamentais na prática docente.

É importante destacar que o questionário foi aplicado na mesma turma em que realizei o estágio de docência, requisito parcial para conclusão do curso de especialização em 
educação, com habilitação para docência, do IFSUL, Campus Pelotas. Observo que a convivência do estágio contribuiu para que a turma se sentisse mais à vontade com a pesquisadora/professora, pois quando expliquei os objetivos da pesquisa eles ficaram muito interessados e prontamente se disponibilizaram a participar. O questionário foi aplicado durante a última aula do estágio e eles tiveram o tempo necessário para responder as questões na aula. É importante evidenciar que todos os estudantes autorizaram a publicação das informações apresentadas nos questionários.

\section{Estudos sobre o bom professor}

Não são recentes os debates e as discussões sobre o que são "bons professores". Mialaret (1981) definiu o bom professor como aquele que domina a matéria que leciona e constrói uma situação que possibilita aos discentes apropriar-se dela de forma eficaz. Segundo Loureiro (1986), o bom professor deve promover nos alunos a "aptidão para ser tudo o que pode ser”. Dessa maneira, é atribuída aos docentes não apenas a responsabilidade pela construção do conhecimento específico de sua área, mas também a responsabilidade pelo desenvolvimento pleno do estudante. E ainda, para Cortesão (1982), o professor, além de atuar nos vários contextos da educação, deve também ser capaz de intervir na escola, estimulando a interação com a comunidade.

Considerando tais autores, é possível afirmar que o bom professor assume a responsabilidade de atuar na área específica do conhecimento, administrar o desenvolvimento pleno do discente e, paralelamente a essas duas, estabelecer a relação com a comunidade.

Com o objetivo de identificar os saberes e as características que são atribuídas a um bom professor, vários estudos já foram realizados no Brasil. Um importante trabalho abordando essa temática foi o de Cunha (2010) sobre o bom professor e sua prática. Silva (1992), tentando compreender o professor bem sucedido, após revisar diversos trabalhos, conclui que os aspectos relacionados ao conteúdo, ao envolvimento, à apropriação da realidade dos alunos e uma prática docente reflexiva seriam os mais importantes.

É fundamental considerar que os debates sobre o papel do professor não se encerram nas questões citadas acima. Hoje, além de suas muitas atribuições, o professor ainda é desafiado pelo crescente e rápido avanço da tecnologia que se constitui como uma nova ferramenta de aquisição do conhecimento e proporciona ao discentes diversas formas de acesso à informação fora do ambiente escolar. Nesse sentido, investigar quais aspectos faz dos 
professores bons profissionais e entender como os professores têm assumido na prática as diversas funções que lhes são atribuídas é relevante para compreender de forma crítica o contexto educacional brasileiro.

A fim de identificar não só os processos pedagógicos que contribuem para a aprendizagem do discente, mas também colaborar com a formação de novos docentes, Ribeiro e Cunha (2010) afirmam que o conhecimento das especificidades científicas é importante, mas insuficiente para responder a complexidade dos problemas que surgem na prática diária da sala de aula. Assim, é importante considerar os diversos sujeitos do universo escolar para analisar a problemática educacional, dentre eles, os educandos que ocupam papel central no processo de ensino-aprendizagem e pouco são considerados no seu potencial avaliativo sobre o cotidiano da sala de aula.

\section{Formação docente no Brasil: um caminho em construção}

Em relação ao processo de formação docente, convém lembrar que o artigo 66 da Lei número 9.344/96 LDBEN diz que “A preparação para o exercício do magistério superior farse-á em nível de pós-graduação, prioritariamente em programas de mestrado e doutorado". Entretanto, Alves (1998) enfatiza que a formação docente ocorre em múltiplas esferas e não apenas em cursos de Pós-Graduação. Nesse contexto, devemos considerar que, embora a titulação seja necessária, ela não é suficiente para o desempenho adequado da docência.

De acordo com a resolução número 2/2015 do CNE a formação inicial e continuada de professores deve ser concedida por instituições de nível superior. Nesse contexto, a formação inicial e continuada destina-se, à preparação e ao desenvolvimento de profissionais para funções de magistério na educação básica - educação infantil, ensino fundamental, ensino médio - e nas diversas modalidades da educação, como: educação de jovens e adultos, educação especial, educação profissional e técnica de nível médio, educação escolar indígena, educação do campo, educação escolar quilombola, educação a distância, entre outras.

Nos últimos anos, a pesquisa de formação de professores vem crescendo significativamente no Brasil e são crescentes também as exigências e expectativas em relação ao trabalho docente.

Durante muito tempo, procuraram-se os atributos ou as características que definiam o "bom professor". Esta abordagem conduziu, já na segunda metade do século XX, à consolidação de uma trilogia que teve grande sucesso: saber (conhecimentos), saber-fazer (capacidades), saber-ser 
(atitudes). Nos anos 90, foi-se impondo um outro conceito, competências, que assumiu um papel importante na reflexão teórica e, sobretudo, nas reformas educativas. Todavia, apesar de inúmeras reelaborações, nunca conseguiu libertar-se das suas origens comportamentalistas e de leituras de matriz técnico e instrumental”. (NÓVOA, 2009, p. 29)

Nesse contexto, é necessário superar definitivamente as metodologias tradicionais de ensino baseadas na transmissão do conhecimento e surge cada vez mais a necessidade de se refletir sobre a importância da formação e das práticas docentes adotadas em nossas escolas.

O conhecimento é busca constante, é prático, se dá graças às experiências práticas com o objeto, é social e trama as relações entre os homens, é histórico, construído pelo ser humano com o passar do tempo. É um processo longo no caminho que leva da ignorância ao conhecimento, além do mais é inacabado. (ALVES, 1996, p. 42)

Para Tardif (2002), a docência não se limita a um único saber. Sendo assim, é constituída por diferentes saberes. Nesse sentido, o autor descreve o professor como "alguém que deve conhecer sua matéria, sua disciplina e seu programa, além de possuir certos conhecimentos relativos às ciências da educação e à pedagogia, e também desenvolver um saber prático baseado em sua experiência cotidiana com os alunos”. (TARDIF, 2002, p. 39)

É importante destacar que ser professor não é transmitir conhecimento. Ser professor vai muito além, exige motivação, dedicação, interesse, compreensão e reflexão. Ensinar é um desafio diário que requer uma formação inicial e formação continuada.

\section{A voz dos estudantes como um caminho para qualificação da prática docente}

Ao tentar identificar características que contribuam com o nosso ensino, entendemos que ouvir os discentes é fundamental. Embora esse não seja um hábito comumente adotado em nossas escolas, entendemos que ele pode contribuir com a reflexão sobre as práticas que vêm sendo desenvolvidas. Ao falar da consulta aos estudantes como colaboradores na comunidade de aprendizagem, Rodriguez (2013, p. 140) afirma que:

A forma da voz dos alunos é considerada uma consulta na qual os professores e estudantes falam sobre as aulas. Os alunos são convidados a oferecer uma retroalimentação sobre o conteúdo do currículo, o estilo das aulas e as propostas metodológicas. Interessa o que os estudantes dizem sobre suas experiências e as decisões tomadas pelos docentes como consequência. A consulta pode fazer com que os estudantes, no fim, envolvam-se com a formação de seus professores. 
Valorizar a voz dos estudantes é possibilitar que eles passem de personagens passivos para personagens ativos no ambiente escolar. É promovê-los a sujeitos responsáveis pelo ambiente pedagógico da sala de aula e promotores da metodologia adequada para a sua própria aprendizagem. Em seu texto, Rodriguez (2013, p. 142) enfatiza que "aquele que não fala está ausente, não decide, é desprovido de voz".

Nesse contexto, acreditamos que uma melhoria das práticas pedagógicas pressupõe o envolvimento dos estudantes, pois eles são parte fundamental do processo educacional. Assim, para a realização dessa pesquisa, foi aplicado um questionário na turma do sétimo semestre do curso Técnico em Química do IFSul, modalidade integrada, com três questões que foram cuidadosamente pensadas.

Inicialmente, pedimos que os estudantes pensassem no melhor professor de Química que eles tiveram no IFSul e respondessem quais as características eles achavam fundamentais em um bom professor de Química. Na segunda questão, perguntamos quais as características eles atribuíam a uma boa aula de Química. Ainda buscando melhor ilustrar a prática docente do bom professor, elaboramos uma terceira questão, pedindo que eles relatassem uma situação de sala de aula que demonstrasse a prática de um bom professor de Química.

Após a aplicação dos questionários, as respostas foram categorizadas e entre as expressões mais usadas pelos alunos, aos serem questionados sobre as características do bom professor de Química, surgiram as seguintes: "possuir uma boa didática", "ter respeito pelos alunos", "rígido", "amoroso", "disposição a ensinar", "mais do que simplesmente ensinar o aluno, ser paciente e ser amigo", "saber compartilhar o conhecimento sem atrapalhar os alunos", "dedicação", "possua amor pelo que faz", "que saiba ensinar o aluno a pensar sozinho", "impor autoridade sem menosprezar o aluno". As respostas foram agrupadas, conforme os gráficos abaixo, em quatro categorias: (I) didática docente; (II) relações afetivas; (III) formação e (IV) metodologia. O número de vezes que cada característica foi mencionada está entre parênteses.

Sobre a didática docente, os estudantes consideram fundamental o professor possuir boa didática (10); propiciar um espaço para os alunos tirarem as dúvidas (4); ser rígido (3); solícito (2); gostar da profissão (2); dinâmico (2); exigente (2); mantém a atenção da turma (1); estar aberto a críticas e sugestões (1); impõe autoridade, mas sem menosprezar os alunos (1); organizado (1); interage com a turma, mas tem controle sobre a aula (1). 


\section{Gráfico 1. Características relacionadas à didática docente.}

Didática docente
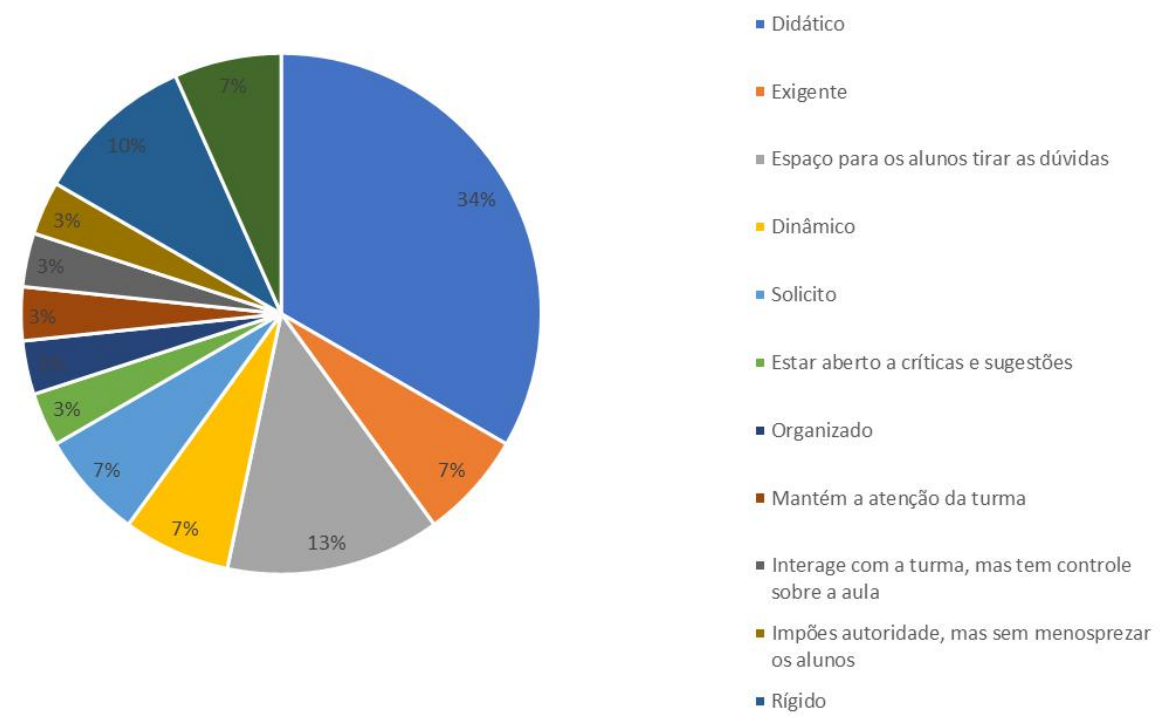

Fonte: As autoras

Cunha (2010), ao tratar do trabalho docente na educação de Nível Superior e Médio, detectou que, para os discentes, o bom professor é aquele que domina o conteúdo, escolhe a forma adequada de apresentar a matéria e tem um bom relacionamento com o grupo. Em nosso trabalho, percebemos que a concepção dos discentes a respeito de um bom professor considera além destes a questão afetiva, pois a maioria dos discentes disse que um bom professor é amigo. Entretanto, nossos estudantes consideram que a forma de compartilhar o conhecimento é mais importante do que o conhecimento específico da disciplina, pois para eles uma boa didática foi a característica que mais atribuíram ao bom professor de Química. Essa característica pode ser evidenciada através da fala de um discente pesquisado: "o bom professor deve fazer com que os alunos gostem da sua matéria e sintam prazer em estudar" (estudante 1 do grupo em análise).

Recentemente, diversos trabalhos vêm tentando identificar as características que os alunos atribuem aos bons professores, principalmente no Ensino Superior. Nesse contexto, um bom professor tem sido descrito pelos estudantes principalmente como aquele que é didático, atualizado e apresenta domínio do conteúdo.

Para CARDOSO (2015), a didática é um indicador do bom professor. Como podemos ver a seguir: 
[...] um bom professor, aquele que sabe como ensinar e quais os procedimentos e recursos são mais adequados ao trabalho com cada conteúdo. Nem sempre está aliada a utilização de recursos, como multimídia. O mais importante é saber seduzir e prender a atenção do, tornar a aula mais interessante com base em escolhas variadas e adequadas de técnicas e de recursos materiais. Para isso, é necessário conhecer técnicas variadas para atender objetivos diversos. (CARDOSO, 2015, p. 9)

A exigência é outra característica que os estudantes têm relacionado como importante. Nesse sentido, FREIRE (2011) afirma que:

[...] o bom professor é o que consegue, enquanto fala, trazer o aluno até a intimidade do movimento do seu pensamento. Sua aula é assim um desafio e não uma cantiga de ninar. Seus alunos cansam, não dormem. Cansam porque acompanham as idas e vindas de seu pensamento. (FREIRE, 2011, p. 83)

Além disso, segundo Cunha (2010), os alunos querem um professor competente e não um professor bonzinho. "O aluno valoriza o professor que é exigente, que cobra participação e tarefas. Ele percebe que esta é também uma forma de interesse se articulada com a prática cotidiana da sala de aula" (CUNHA, 2010, p. 63).

Entre as questões afetivas, foram consideradas mais importantes o professor ser amigo (9); paciente (7); compreensivo (3), bem humorado (2); flexível (1); ter boa vontade (1).

\title{
Gráfico 2. Características que os estudantes atribuem ao bom professor em relação à afetividade.
}

\section{Relações afetivas}

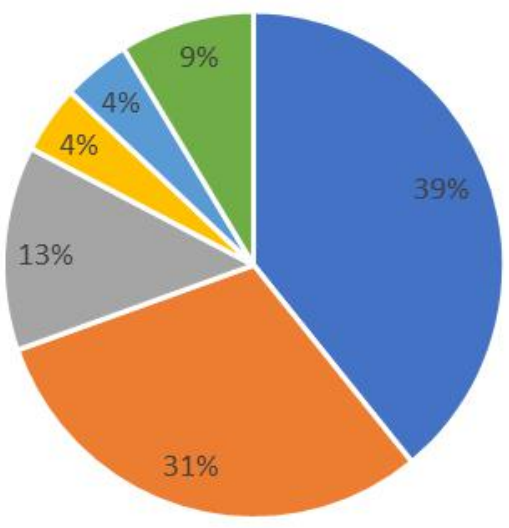

\author{
- Amigo \\ - Paciente \\ - Compreensivo \\ - Flexível \\ - Boa vontade \\ - Bom humor
}

Fonte: As autoras 
Em relação à afetividade, em nosso trabalho, as características afetivas também foram destacadas pelos estudantes que definiram um bom professor de Química como "amigo", "paciente" e "compreensivo".

Freire (2011) nos ajuda a compreender a relevância da afetividade ao relacioná-la com o desenvolvimento cognitivo e ao afirmar que afetividade e aprendizagem andam em parceria.

Preciso descartar como falsa a separação radical entre seriedade docente e afetividade. Não é certo, sobretudo do ponto de vista democrático, que serei tão melhor professor quanto mais severo, mais frio, mais distante e "cinzento" me ponha nas minhas relações com os alunos, no trato dos objetos cognoscíveis que devo ensinar. A afetividade não se acha excluída da cognoscibilidade. (FREIRE, 1996, p. 141)

Em relação às questões interpessoais, Nogueira (2012) enfatiza que o professor pode ao mesmo tempo evitar estímulos negativos, como ansiedade e raiva, e promover emoções positivas, como o respeito, fazendo, assim, com que os alunos se sintam capazes e motivados a participar da aula.

Em seu trabalho, Cunha (2010) diz que "quando o professor chega perto do aluno, quando o chama pelo próprio nome, há uma interação que faz o aluno se sentir sujeito do ato de aprender. Isto o anima a interferir no conhecimento, ainda mais quando o professor usa palavras de incentivo à participação" (CUNHA, 2010 p. 145).

Em relação à influência de novas tecnologias na prática docente, um trabalho realizado em 2012 por Nogueira teve como objetivo captar as características de um bom professor ou professor exemplar para a geração Y (ou Millennials), que é caracterizada por serem proficientes em tecnologia, assim como os nossos sujeitos de pesquisa. No trabalho de Nogueira (2012), foi demonstrado que as características do conhecimento teórico e a capacidade de explicar o conteúdo foram consideradas as mais importantes por alunos do curso de Ciências Contábeis.

Em nosso estudo, nenhuma característica relacionada ao uso de novas ou diferentes tecnologias foi associada pelos discentes a características de um bom professor. As tecnologias não eram o foco de nosso estudo, no entanto tínhamos a expectativa que elas compusessem o cenário das boas práticas docentes. O que não ocorreu, pois o nosso grupo de investigação manteve o foco na didática docente de forma ampla.

Considerando a formação do docente, as características destacadas pelos estudantes foram o conhecimento dos professores (3) e a inteligência (1). Existe uma expectativa dos 
discentes em relação aos professores e às suas aulas. Essas expectativas são baseadas nas suas experiências e vivências escolares, bem como no seu contexto social. "Os conceitos sobre o que constitui um 'bom professor' variam ao longo do tempo, de cultura para cultura, e até mesmo dentro de uma determinada cultura" (CONNELL, 2010, p. 166).

\section{Gráfico 3. Características relacionadas à formação do Bom professor.}

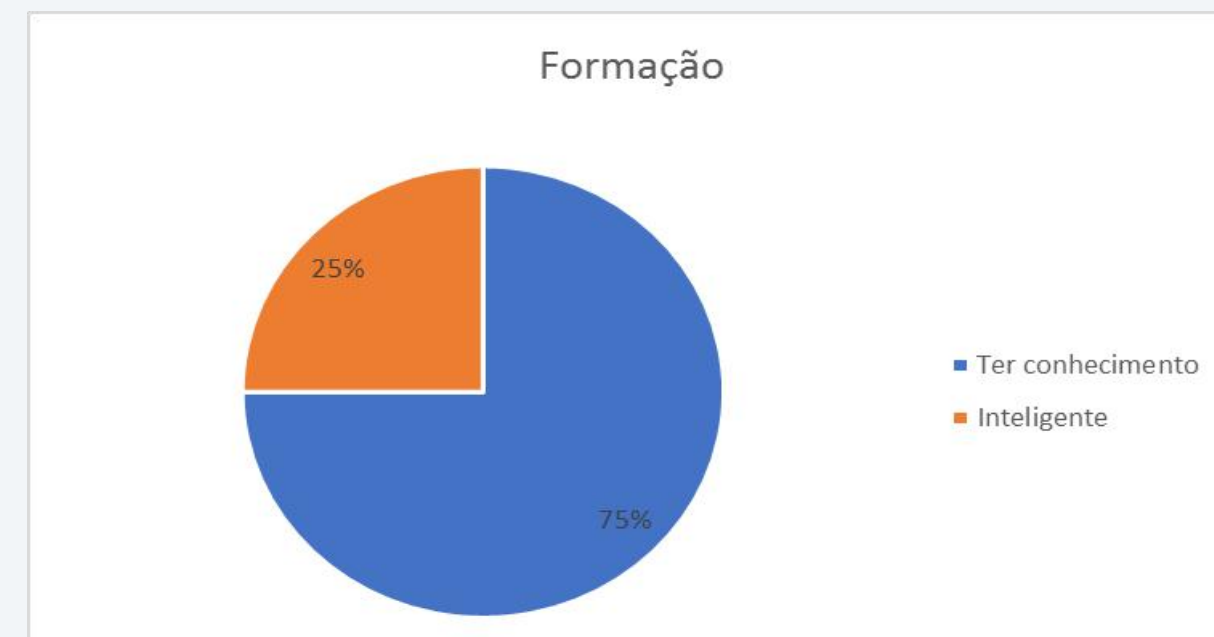

Fonte: As autoras

Um último aspecto considerado em relação às características do bom professor foi a metodologia. Nessa categoria, os estudantes mencionaram como importante que o professor saiba respeitar a turma (2); seja dedicado (1); comprometido (1); interessado (1) e esteja preocupado com o aluno (1).

Gráfico 4. Aspectos relacionados com a metodologia do Bom professor.

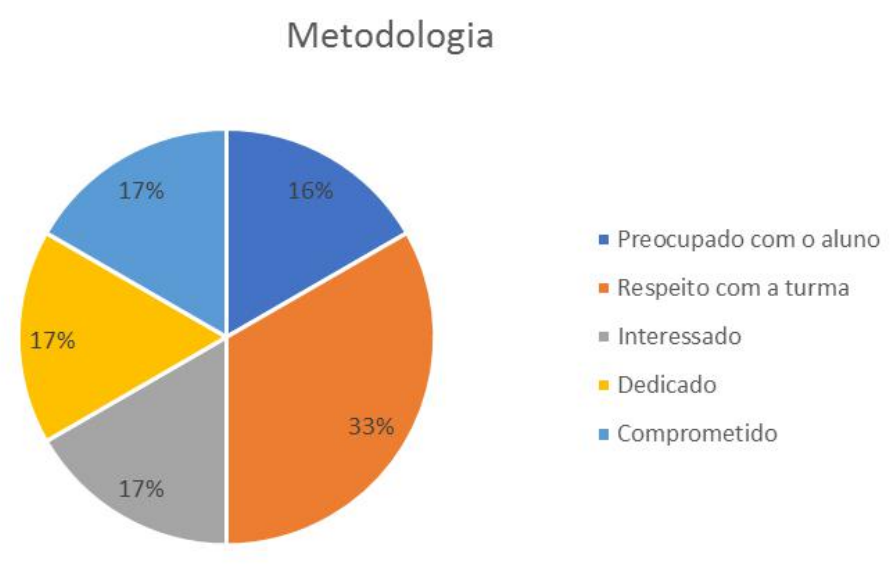

Fonte: As autoras 
Em relação ao comprometimento, Freire afirma que:

[...] se perguntado por um aluno sobre o que é "tomar distância epistemológica do objeto", lhe respondo que não sei, mas que posso vir a saber, isso não me dá autoridade de quem conhece, me dá a alegria de, assumindo minha ignorância, não ter mentido. E não ter mentido abre para mim junto aos alunos um crédito que devo preservar. (FREIRE, 2011, p. 94)

Assim, é importante considerar que o professor não deve "chutar" uma resposta, ou simplesmente "enrolar" o aluno, pois ele tem um comprometimento com a aprendizagem desse estudante. Ainda devemos considerar que é papel do educador instigar a curiosidade e os questionamentos nos educandos, consequentemente, maior deve ser sua dedicação e comprometimento para responder a esses questionamentos.

Contudo, cabe observar que o primeiro contato do docente com a escola é na sua experiência discente e não apenas no seu processo de formação profissional. Considerando tal aspecto, Tardif (2000) enfatiza que o "saber experiencial se transforma muito cedo em certezas profissionais, em truques do ofício, em rotinas, em modelos de gestão da classe e de transmissão da matéria" (TARDIF, 2000, p. 14). Sendo assim, sempre que o professor não souber como agir ele pode acessar os modelos presentes na sua memória e adotar práticas automatizadas, por vezes desconexas da concepção por ele defendida.

Percebemos que os estudantes também não atribuíram ao bom professor características como ser crítico ou ser reflexivo. Entretanto, acreditamos que desenvolver a criticidade e estimular os educandos a serem reflexivos é essencial. Nesse sentido, Cunha (2010) nos diz que:

[...] os papéis escolares estão definidos ideologicamente também na sociedade, identificados com a classe dominante, passando pela forma de produção e distribuição do conhecimento. Os professores vivem num ambiente complexo onde participam de múltiplas interações sociais no seu dia a dia. São eles também frutos da realidade cotidiana das escolas, muitas vezes incapazes de fornecer uma visão crítica aos alunos, porque eles mesmos não a têm, porque se debatem no espaço de ajustar seu papel à realidade imediata da escola, perdendo a dimensão social mais ampla da sociedade. (CUNHA, 2010, p. 58).

“Há que se reconhecer a complexidade de traduzir o 'Bom professor' em um conceito acabado" (VENTURA, 2011, p. 101). Optamos por nos aproximar desse conceito, a partir da voz dos estudantes, pois compreendemos que explicitar e considerar a voz desses sujeitos é 
uma forma de problematizar aspectos que precisam ser qualificados na formação e na prática docente.

\section{O bom professor é aquele que dá uma boa aula}

Acreditamos que o bom professor é aquele que dá uma boa aula; então, além de analisar as características que os estudantes atribuem ao bom professor, procuramos identificar as que eles acham importantes em uma boa aula de Química. Nessa questão, as respostas foram agrupadas em cinco categorias: (I) em relação ao registro do conteúdo; (II) em relação à forma com que o conteúdo é apresentado aos alunos; (III) em relação às características da aula; (IV) em relação à organização da aula e (V) referente às relações pessoais sejam elas professor-aluno ou entre os próprios alunos.

Quando questionados sobre a boa aula, os discentes acharam importante o uso do quadro (7) e também mencionaram em menor número o uso de apostila (1). Com esse destaque, nota-se a preocupação dos discentes com o registro do conteúdo e consequentemente a boa aula de química assume uma identidade prospectiva, ou seja, deve propiciar mecanismos para que o estudante retorne aquele conteúdo quando necessário.

\section{Gráfico 5. Características relacionadas à boa aula de Química em relação ao registro do conteúdo.}

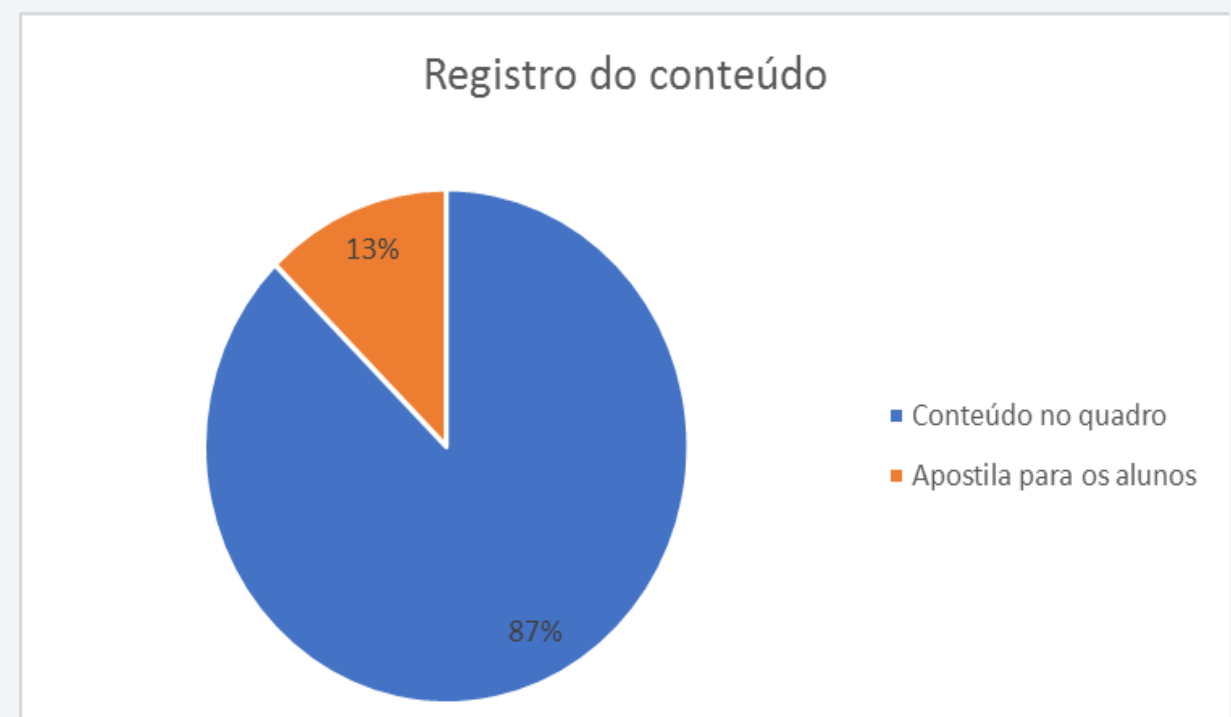

Fonte: As autoras 
Além disso, é importante problematizar que quando o estudante afirma que uma boa aula "deve conter matéria no quadro e apostila", pode estar influenciado pela referência já consolidada em seu cotidiano que valoriza uma postura passiva do discente no processo de ensino-aprendizagem. Entretanto, acreditamos que o educador deve ser capaz de aguçar no educando a sua curiosidade, desenvolvendo nestes um saber construído por eles e não apenas transmitido para eles.

Outro aspecto que os alunos consideraram importante, além da forma de registro do conteúdo, foi a forma de apresentação desse conteúdo. Nesse contexto, os estudantes disseram que o uso de exemplos (4) e de imagens (1) contribui para uma boa aula. Além disso, eles consideraram importante que o professor estimule o discente a desenvolver o seu próprio raciocínio (1) e que apresente o conteúdo de forma inovadora (1).

\section{Gráfico 6. Características relacionadas à apresentação do conteúdo.}

Apresentação do conteúdo
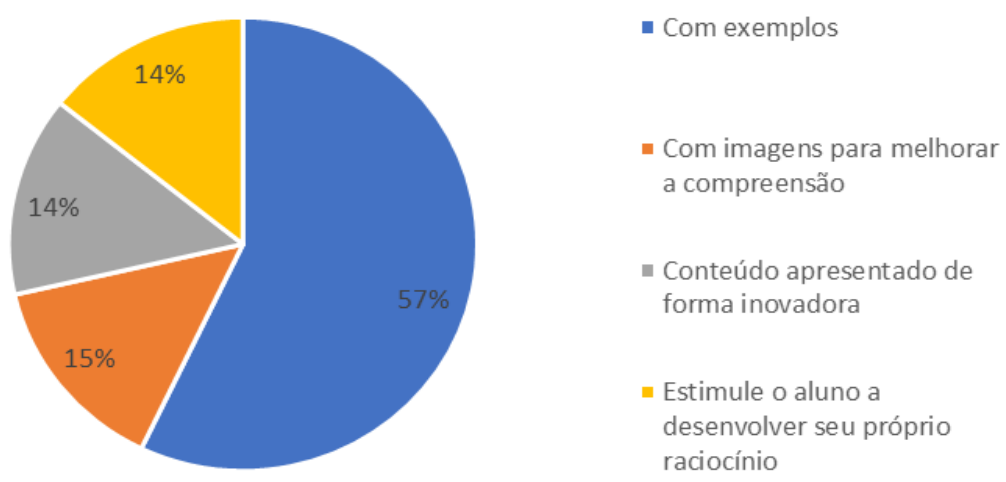

Fonte: As autoras

No trabalho de Cunha (2010), os alunos relataram que a forma de apresentar o conteúdo era uma característica importante do bom professor. Quando questionados sobre as características de uma boa aula, em nosso trabalho, os estudantes acharam que a realização de aulas práticas e o uso de exemplos são a melhor forma de apresentação do conteúdo. Os discentes também consideram importante que as explicações teóricas enfatizem a aplicação prática do conteúdo trabalhado, como pode ser observado na fala do estudante pesquisado: "apresentar uma aplicação prática do que já foi apresentado" e "relacionar com situações cotidianas". 
Em relação às características da boa aula, os estudantes acharam importante que a aula seja dinâmica (7), didática (6), divertida (2), motivadora (1), interessante (1) e que acrescente conhecimento (1).

\section{Gráfico 7. A visão dos estudantes em relação às características da boa aula de Química.}

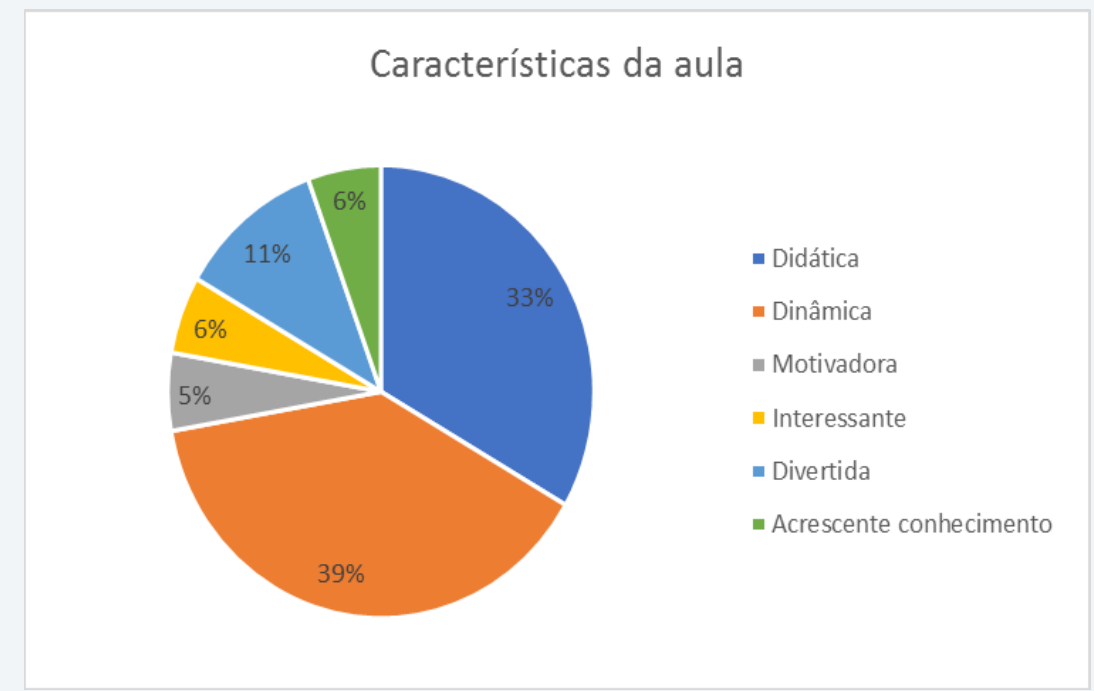

Fonte: As autoras

A forma com que o professor organiza sua aula também influencia para que a aula seja considerada boa. Nesse sentido, os discentes acham importante que os docentes se preocupem em esclarecer as dúvidas (2), tenham calma (1), tempo para ministrar o conteúdo (1) e corrijam os exercícios em aula (1). Os educandos também mencionaram como importante a realização de trabalhos em grupo (1) e terem aula de apoio (1).

\section{Gráfico 8. Características relacionadas à organização da aula.}

Organização da aula

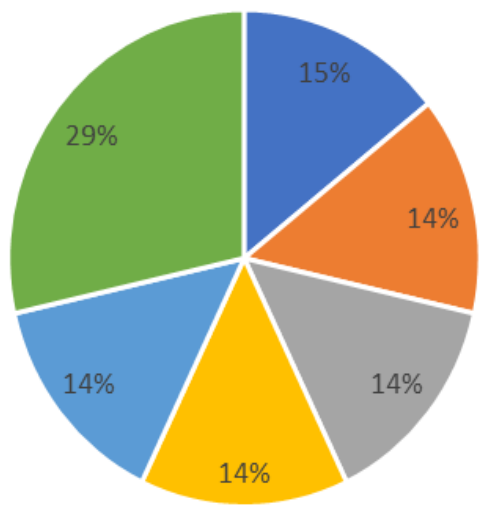

\footnotetext{
- Tempo para ministrar os conteúdos

- Calma

- Dar exercícios e corrigir em aula

- Trabalho em grupo

- Aula de apoio

- Esclarecimento de todas as dúvidas
}

Fonte: As autoras 
Um último aspecto que foi relacionado com a boa aula foram as relações pessoais. Não apenas a interação professor aluno foi considerada importante (2), mas também a relação entre os próprios estudantes (1).

\section{Gráfico 9. A influência das relações pessoais na boa aula de Química}

\section{Relações pessoais}

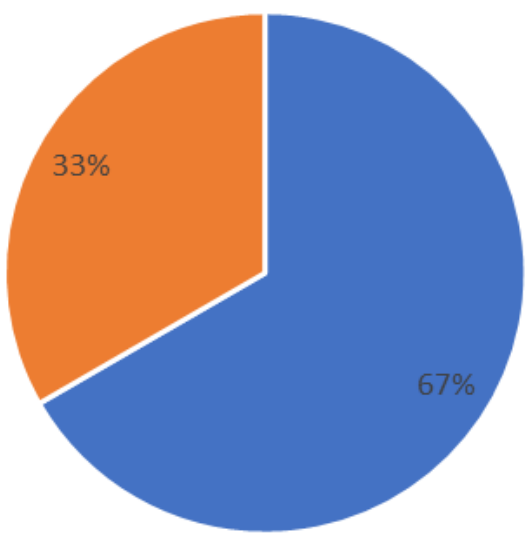

- Interação professor aluno

- Companheirismo dos colegas

Fonte: As autoras

É importante aqui considerarmos que as relações pessoais e afetivas não foram consideradas pelos estudantes apenas como características de um bom professor, mas também de uma boa aula de Química. O que nos indica a valorização dos discentes a uma prática vinculada ao cotidiano e as particularidades de cada um. Ponderar sobre até que ponto os professores de Química implementam essa prática é uma questão que vai além do propósito deste estudo, mas é extremamente relevante para compreensão da docência na área específica. Considerando tal contexto, cabe ressaltar os discentes atribuíram a uma boa aula de Química a boa interação aluno-professor e também a boa interação entre os próprios alunos.

Ainda, para melhor ilustrar a ideia dos alunos sobre o bom professor, elaboramos, em nosso questionário, uma pergunta pedindo que eles relatassem uma situação de sala de aula que demonstrasse a prática de um bom professor de Química. Nessa questão, podemos perceber que, além das características já discutidas, o conceito do bom professor, muitas vezes vai além da sala de aula, como relatado pelo aluno abaixo: 
A situação não foi bem na sala de aula, pois então, fiz uma prova, onde zerei a mesma devido às configurações da calculadora estar alterada, porém mostrava desenvolvimento correto, fui conversar com o professor que me disse estar tudo certo, porém o resultado final não bate; para quem nunca tinha zerado, foi um choque; ele me disse: posso te dar 2,5 ou tu fazer a avaliação e sair muito melhor, então aceitei o zero e tirei 9 sobre 10 . É bom quando quem te ensina acredita em ti e vê o potencial, porque às vezes nem nós mesmos acreditamos. (Estudante 2 do grupo em análise)

Além disso, os estudantes enfatizaram a importância do diálogo: “o professor conversou com a turma, ouviu o que cada um tinha a dizer e isso não atrapalha em nada o rendimento" (estudante 3 do grupo em análise).

Uma aula que no início todos tinham medo, pois sempre teve um bom índice de reprovação, mas com o passar do tempo foi visto que é assim que realmente se deve ser, exigir do aluno para ele dar o melhor de si. Eu particularmente reprovei nessa disciplina, mas posso confessar que é a minha matéria preferida e aprendi a dar o meu melhor com o incentivo desse professor. (Estudante 4 do grupo em análise)

Por fim, considerando a voz dos estudantes, percebemos que são muitas as características que os discentes atribuem ao bom professor e à boa aula de Química. Nesse sentido, em suas aulas, o professor deve contemplar um conjunto de características relacionadas aos conhecimentos pedagógicos, aos conhecimentos específicos da área e às relações humanas.

\section{Considerações Finais}

O objetivo do presente trabalho foi analisar as concepções dos estudantes sobre o bom professor e a boa aula de Química a fim de identificar características que possam contribuir tanto com a prática docente de professores em formação quanto com as práticas pedagógicas que já vêm sendo adotadas nas nossas escolas. Consideramos que ouvir os estudantes, conhecer suas perspectivas e concepções é essencial para nos direcionar nesse processo.

A partir da voz dos discentes, podemos identificar que o bom professor precisa conectar características relacionadas ao domínio do conteúdo, a uma boa didática e a características afetivas. Além disso, pelo estudo bibliográfico realizado, foi possível observar que algumas dessas características vêm se mantendo ao longo do tempo como a forma de apresentação do conteúdo, bem como algumas das características ligadas à relação professor e 
aluno. Entretanto, para os estudantes pesquisados, as características relacionadas com a didática e a forma de compartilhamento do conteúdo são importantes e percebe-se também a preocupação em relação à questão tempo. Nesse sentido, os estudantes atribuíram, às características de um bom professor, conceder espaço para tirar as dúvidas e o tempo para ministrar o conteúdo como características de uma boa aula. Além disso, os discentes enfatizaram como importante que o professor não apenas passe os exercícios, mas que tenha tempo para corrigi-los em aula.

Percebemos que são muitas as características que os estudantes atribuem a um bom professor e a uma boa aula de Química; entretanto, sabemos que maior ainda é o desafio dos professores para alcançar e harmonizar todas essas habilidades em suas aulas. Porém, entendemos que para que haja uma educação de melhor qualidade é necessário que os professores estejam abertos a ouvir os discentes, com o objetivo de aprimorar sua prática docente.

Esperamos que, ao problematizar aqui as questões relacionadas ao bom professor e à boa aula de Química, possamos favorecer uma reflexão sobre as práticas adotadas nas nossas salas de aula e contribuir para avanços no processo de ensino-aprendizagem.

Em nosso trabalho, identificamos que, para os estudantes, o conceito do bom professor de Química é multidimensional e envolve, ao mesmo tempo, características relacionadas à didática e à afetividade. É importante aqui considerarmos que os conceitos do bom professor $\mathrm{e}$ da boa aula de Química podem mudar em diferentes escolas e até mesmo dentro da mesma escola em diferentes turmas, pois depende dos discentes, das suas vivências, dos valores sociais, entre outros aspectos relevantes.

Por fim, não temos o objetivo de encerrar aqui as discussões sobre o bom professor ou a boa aula de Química, tampouco queremos sobrepor nossos resultados aos encontrados em pesquisas anteriores. Nosso objetivo foi contribuir com as reflexões sobre o tema, considerando uma realidade específica; a partir de tal intenção, esperamos ter contribuído para as reflexões acerca da qualificação da prática docente.

\section{Referências}

ALVES, Nilda. Trajetórias e redes na formação de professores. Rio Janeiro: DP\&, 1998.

ALVES, Nilda. Formação de professores: pensar e fazer. 4ª ed. São Paulo, Cortez, 1996. 
BARROS, J. M. P. Os caminhos do bom professor de direito. Disponível em: http://www.conteudojuridico.com.br/?artigos\&ver=2.22449. Acesso em: 17 de maio de 2017. BRASIL. Congresso Nacional. Lei Federal n. 9.394/96. Estabelece as Diretrizes e Bases da Educação Nacional. Disponível em: <http://www.planalto.gov.br/ccivil_03/leis/L9394.htm>. Acesso em: 29 mai.2017.

BARROS, J. M. P. Conselho Nacional de Educação. Parecer n ${ }^{\circ} 2$ de 1 de julho de 2015. Define as Diretrizes Curriculares Nacionais para a formação inicial em nível superior (cursos de licenciatura, cursos de formação pedagógica para graduados e cursos de segunda licenciatura) e para a formação continuada. Disponível em: $<$ http://portal.mec.gov.br/index.php?option=com_docman\&view=download\&alias=17719res-cne-cp-002-03072015\&category_slug=julho-2015-pdf\&Itemid=30192>. Acesso em: 29 mai. 2017.

CARDOSO, M. R. O bom professor universitário do século XXI e sua prática. Cadernos da Fucamp, v.14, n.15, 2015. p. 133-148.

CONNELL, R. Bons professores em um terreno perigoso: rumo a uma nova visão da qualidade e do profissionalismo. Traduzido por Carlos Malferrari. Educação e Pesquisa, São Paulo, v. 36, n. especial, 2010. p. 165-184.

CORTESÃO, L. Extratos de: proposta de um currículo para a formação de formadores. Professor, Lisboa, n. 38, p. 57-59, 1982.

CUNHA, M. I. O bom professor e sua prática. $24^{\text {a }}$ ed. Campinas, SP: Papirus, 2010.

FREIRE, P. Pedagogia da autonomia: saberes necessários à prática educativa. $43^{\mathrm{a}}$ ed. São Paulo: Paz e Terra, 2011.

GIL A. C. Métodos e técnicas de pesquisa social. $6^{\text {a }}$ ed. São Paulo: Atlas S. A., 2008.

LOUREIRO, J. E. Elementos para uma política de formação de formadores em educação. Ludens, Lisboa, v. 10, n. 3/4, 1986. p. 7-10.

MiAlARET, G. A Formação de Professores. Coimbra: Livraria Almedina, 1981.

MINAYO, M. C. S. (org.). Pesquisa social: teoria, método e criatividade. Rio de Janeiro: Vozes, 2012.

NOGUEIRA, D. R. O bom professor na perspectiva da geração Y: uma análise sob a percepção dos discentes de Ciências Contábeis. $11^{\circ}$ Congresso USP de Controladoria e Contabilidade, V. 31, n. 3, 2012. p. 37-52.

NÓVOA, A. Formação de professores e profissão docente In: NÓVOA, Antonio. Os professores e sua formação. Lisboa: Publicação Dom Quixote, 1992.

NÓVOA, A. Professores imagens do futuro presente. Lisboa: Educa, 2009. 
RIBEIRO, M. L.; CUNHA, M. I.. Trajetórias da docência universitária em um programa de pós-graduação em Saúde Coletiva. Interface - Comunicação, Saúde, Educação. v. 14, n. 32, Botucatu, SP, 2010.

RODRIGUEZ, J. B. M. O currículo como espaço de participação: a democracia escolar é possível? In: SACRISTÁN, José Gimeno: Saberes e incerteza sobre o currículo. Porto Alegre: Penso, 2013.

SANTOS, M. V. P. A caracterização do "bom professor" conforme a visão dos alunos de uma escola pública do estado de São Paulo. Monografia Universidade Presbiteriana Mackenzie. São Paulo, 2010.

SILVA, M. H. G. F. D. O professor como sujeito do fazer docente: a prática pedagógica nas $5^{\text {as }}$ séries, 1992. (tese Doutorado em Educação) - Faculdade de Educação, USP, São Paulo, 1992.

TARDIF, M. Saberes profissionais dos professores e conhecimentos universitários. Elementos para uma epistemologia da prática profissional dos professores e suas consequiências em relação à formação para o magistério. Revista Brasileira de Educação, n¹3, 2000.

TARDIF, M. Saberes Docentes e Formação Profissional. Petrópolis: Vozes, 2002.

VENTURA, M. C. A. A. et al. O "bom professor" - opinião dos estudantes. Revista de Enfermagem Referência, Coimbra, III Série, n. 5, dez. 2011. p. 95-102.

\section{$\underline{\text { SOBRE AS AUTORAS }}$}

\section{Marcelle Moura Silveira}

Doutoranda em Biotecnologia pela Universidade Federal de Pelotas (UFPel). Bacharel em Farmácia e Bioquímica. Especialista em Educação Profissional com Habilitação para a Docência pelo IFSul/Campus Pelotas. Bolsista de Doutorado Sanduíche na Universidade de Cambridge, Reino Unido. E-mail: adriana.adrileon@gmail.com

\section{Adriana Duarte Leon}

Doutora em Educação pela Universidade Federal de Minas Gerais (UFMG). Professora Programa de Pós-Graduação em Educação e Tecnologia do Instituto Federal SulRio-Grandense (IFSul). E-mail: adriana.adrileon@ gmail.com 